Research Article

\title{
Well-Dispersed Silica Fume by Surface Modification and the Control of Cement Hydration
}

\author{
Rui Ma, ${ }^{1}$ Liping Guo $\mathbb{D}^{1,2}$ Wei Sun, ${ }^{1,2}$ and Zhidan Rong $\mathbb{D}^{1,2}$ \\ ${ }^{1}$ School of Materials Science and Engineering, Southeast University, Nanjing 211189, China \\ ${ }^{2}$ Jiangsu Key Laboratory of Construction Materials, Advanced Civil Engineering Materials Collaborative Innovation Center, \\ Nanjing 211189, China \\ Correspondence should be addressed to Liping Guo; guoliping691@163.com
}

Received 15 April 2018; Accepted 3 July 2018; Published 6 August 2018

Academic Editor: Yinshan Tang

Copyright (c) 2018 Rui Ma et al. This is an open access article distributed under the Creative Commons Attribution License, which permits unrestricted use, distribution, and reproduction in any medium, provided the original work is properly cited.

\begin{abstract}
Silica fume (SF) is a valuable nanoscaled industrial by-product used in cementitious materials owing to its filling and pozzolanic effect. However, the heavy agglomeration of SF is a severe and common problem. In this study, surface modification with polyacrylic acid (PAA) was applied on SF to achieve a better dispersion and to optimize the hydration process of cement at early age. The particle size distribution and surface properties of SF, as well as the cement hydration with modified SF, were investigated. The results demonstrated that the agglomeration of SF particles was efficiently mitigated by the surface treatment with PAA, and the acceleration effect of SF was delayed by the resistance of the surface layer at early age. However, the grafted PAA layer eventually dropped in alkali solution after 6 hours, and the hydration rate was increased again and continued for long time. This work indicated that surface-modified SF was well dispersed and was able to regulate the hydration rate of cement.
\end{abstract}

\section{Introduction}

Nanomaterial is a new generation product. Its outstanding properties have drawn much attention in improving the performance of cementitious materials and have developed rapidly in decades [1-6]. The nanomaterials in cementitious composites can efficiently fill small voids to densify the cement paste matrix with the nanoscaled particles, accelerate cement hydration by supplying large active specific surface, and generate additional C-S-H gels to optimize the microstructure benefiting from the pozzolanic reactivity [717]. Nevertheless, the expensive cost and the low productive capacity of artificial nanomaterials limited their wide application in cementitious materials. It has been shown that many industrial by-products, such as silica fume (SF), metakaolin, and ground rice husk ash, are composed of active nanoscaled particles [18-22] and can be used as ecological nanomaterials. The mean particle size of SF can reach about $200 \mathrm{~nm}$, and the specific surface area is large as
$20000 \mathrm{~m}^{2} / \mathrm{kg}[23,24]$. Applying SF in cementitious materials not only brings the benefits as nanomaterials but also decreases the production cost and the environmental impact [22, 25-27]. However, as industrial by-products, heavy aggregation commonly exists in SF product, impairing its filling effect and reducing its available active surface area $[28,29]$ so that well-dispersed SF will take advantages efficiently on its reinforcement for cementitious materials. In addition, nanoparticles-accelerated cement hydration with a rapid heat release at early age, which may cause the structural damage and restrict the strength development at later age $[30,31]$. To solve this issue, the nanomaterials with hydration control effect are preferred.

Surface modification is an efficient method to improve the particle dispersion and transform the surface properties, which is frequently used for nanomaterials [32-35]. The functional group grafted on the surface feasibly isolates particles by the charge repulsion and the steric hindrance effect [36], and the surface properties can be precisely and 
purposively determined by the modification agent with the specific experimental procedure. However, the surface modification method is rarely used in cementitious materials as reported in $[37,38]$. This may be because that the complex reaction products and high alkali circumstance are generated by cement hydration, which could reduce the stability of the surface modification agents. In addition, the polymer surface modification agents may disturb the cement hydration with unclear interaction. Therefore, a suitable surface agent is important for cementitious materials surface modification. Polyacrylic acid (PAA) with short branch chain of carboxyl groups is a common surface modification agent [39-41]. The hydrophilic groups of PAA can isolate nanoparticles by its charge repulsion and the steric hindrance after grafted on the particle surface and form a hydrophilic layer around the particle. In addition, the molecular structure and functional group of PAA are similar to polycarboxylate superplasticizer $[42,43]$ so that it may have minor interruption to cement hydration. Amino-silane coupling agent with amino group and silane group on the end of the molecule is a common bridge agent, which can be used to combine the inorganic particles and polymers $[44,45]$.

In this study, a simple and efficient surface modification method was developed to disperse the agglomerate SF. Polyacrylic acid (PAA) and $\gamma$-aminopropyltriethoxysilane were selected as the modification agent and the bridge agent, respectively. In addition, the efficiency of particle dispersion was tested by changing the dosage of agents. The effect of modified SF particles on cement hydration was also investigated to reveal the influence of the surface modification agent in cementitious materials.

\section{Materials and Methods}

2.1. Materials and Procedure. Commercial silica fume (SF) from Elkem Company was the main material in this study. The chemical and physical properties of SF are shown in Table 1. Polyacrylic acid (PAA) 50\% water solution from Aladdin with the mean molecular weight of 3000 and $\mathrm{KH}-$ 550 of commercial $\gamma$-aminopropyltriethoxysilane bought from Nanjing Jingtianwei Chemical Co., LTD were used as the dressing agents. The molecule structures of the two agents are shown in Figure 1, and the physical index is listed in Table 2. Ultrapure water was used to prepare aqueous solution in the synthesis process. PI 52.5 Portland cement was used as binder materials. The chemical composition of cement is listed in Table 3. Polycarboxylate superplasticizer (MELFLUX 2651F, BASF) with the waterreducing rate of $40 \%$ was used to adjust the workability of fresh pastes.

In the preparation procedure, $\mathrm{SF}(s, \mathrm{~g})$ was dispersed in $500 \mathrm{~mL}$ ultrapure water by ultrasonic treatment for $30 \mathrm{~min}$. Then, $\mathrm{KH}-550(k, \mathrm{~g})$ dissolved in $100 \mathrm{~mL}$ ultrapure water was added into the SF solution slowly and mechanically stirred at $65^{\circ} \mathrm{C}$ for $20 \mathrm{~h}$. Then, PAA water solution $(p, \mathrm{~g})$ was diluted in $100 \mathrm{~mL}$ ultrapure water, added into the SF mixture, and stirred at $65^{\circ} \mathrm{C}$ for another $1 \mathrm{~h}$. The modification procedure is briefly shown in Figure 2. The precipitate was separated by vacuum filtration, washed with ultrapure water and ethanol several times, dried under vacuum at $45^{\circ} \mathrm{C}$, and denoted as MSF. To evaluate the dispersion efficiency, three groups of samples with different dosage of materials were prepared, and the dosages are listed in Table 4.

To produce cement paste, PI 52.5 Portland cement was partly substituted by SF or MSF with $10 \%$ by weight. The water to binder ratio (W/B) was fixed at 0.2 . Polycarboxylate superplasticizer of $1 \%$ by the powder weight was added to improve the workability of fresh paste. The mix proportion detail is listed in Table 5. The fresh mixture was casted and then was steam curried at $85^{\circ} \mathrm{C}$ for 7 days.

2.2. Test Methods. The particle size distributions of SF and MSF were measured by the laser particle size analyser (PSD, Microtrac S3500). The test solution was ethanol. $5 \mathrm{~g}$ of samples was first ultrasonically dispersed in $100 \mathrm{~mL}$ ethanol for $3 \mathrm{~min}$, and then the appropriate amount of the mixture was dropped into the test container. Each sample was analysed twice and output the average result.

To directly observe the morphology of SF particles and hydrated pastes, a scanning electron microscope (SEM, FEI 3D) was used with both secondary electron (SE) mode and backscattered electronic (BSE) mode. Under the SE mode, the SF particles before and after modification were observed; the operating voltage was $20 \mathrm{kV}$, and the work distance was about $6 \mathrm{~mm}$.

The morphology of hydrated products and the hydration degree were also investigated by BSE images. The electron information collected in the BSE mode is sensitive to the element number so that different phases in paste are easy to distinguish by different grey levels.

For the BSE test, the fragments of paste were dried for $48 \mathrm{~h}$ at $40^{\circ} \mathrm{C}$ in vacuum oven, and then the samples were impregnated with epoxy under vacuum until hardened. After this, the samples were successively polished on a sand paper of $20,10,5$, and $2 \mu \mathrm{m}$ and diamond paste of $0.1 \mu \mathrm{m}$. The samples were finally coated with the carbon film to avoid charging during electron scanning. The operating voltage of BSE images was $15 \mathrm{kV}$. For each sample, BSE images with the magnification of 2000 were used to morphology analysis, and more than thirty images were taken for the hydration degree analysis. Each image was digitized to $1536 \times 1024$ pixels. For the hydration analysis, the image processing software (image J) was used to distinguish the grey levels from 0 to 255 in each image and calculate the area fraction of unreacted cement owing to the specific range of grey level. Then the hydration degree of cement was calculated by following equation [46]:

$$
\alpha=\left(1-\frac{V_{t}}{V_{\text {ini }}}\right) \times 100 \%,
$$

where $\alpha$ is the hydration degree of cement and $V_{t}$ and $V_{\text {ini }}$ imply the volume fraction of cement from BSE images and initial volume in mix proportion, respectively. Due to the random and isotropic nature of cement paste, the volume fraction of $3 \mathrm{D}$ real structure is equal to the area fraction of $2 \mathrm{D}$ cross section. 
TABLE 1: Chemical and physical indexes of SF.

\begin{tabular}{cccccc}
\hline & $\mathrm{SiO}_{2}$ content $(\%)$ & L.O.I (\%) & Activity index (\%) & Specific surface area $\left(\mathrm{m}^{2} / \mathrm{g}\right)$ & Specific gravity \\
\hline Silica fume & 95.1 & 0.7 & 85 & 29.9 & 2.3 \\
\hline
\end{tabular}

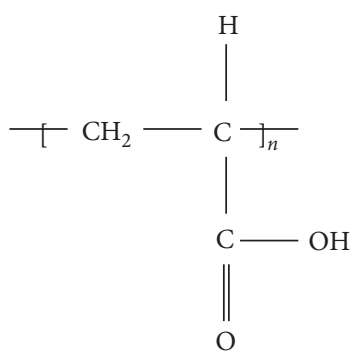

(a)

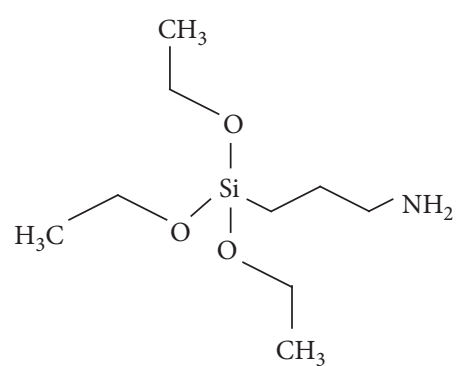

(b)

Figure 1: Abbreviated molecular structure of PAA (a) and KH-550 (b).

TABLE 2: Physical index of PAA and KH-550.

\begin{tabular}{lccccc}
\hline Materials & Molecular weight & Specific gravity & Concentration (\%) & Appearance & Water solubility \\
\hline PAA & $\sim 3000$ & 1.23 & 51.4 & Colourless viscous liquid & Soluble \\
KH-550 & 221.37 & 0.95 & 98.2 & Colourless liquid & Soluble \\
\hline
\end{tabular}

Table 3: Chemical composition of PI 52.5 Portland cement.

\begin{tabular}{cccccccccc}
\hline & $\mathrm{SiO}_{2}(\%)$ & $\mathrm{Al}_{2} \mathrm{O}_{3}(\%)$ & $\mathrm{Fe}_{2} \mathrm{O}_{3}(\%)$ & $\mathrm{CaO}(\%)$ & $\mathrm{MgO}(\%)$ & $\mathrm{SO}_{3}(\%)$ & $\mathrm{K}_{2} \mathrm{O}(\%)$ & $\mathrm{N}_{2} \mathrm{O}(\%)$ & $\mathrm{L} . \mathrm{O} . \mathrm{I}(\%)$ \\
\hline Cement & 20.40 & 4.70 & 3.38 & 64.70 & 0.87 & 1.89 & 0.49 & 0.33 & 3.24 \\
\hline
\end{tabular}

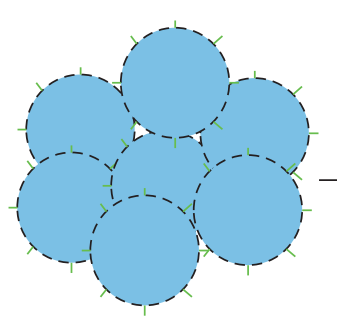

KH-550

$65^{\circ} \mathrm{C}$ for $20 \mathrm{~h}$
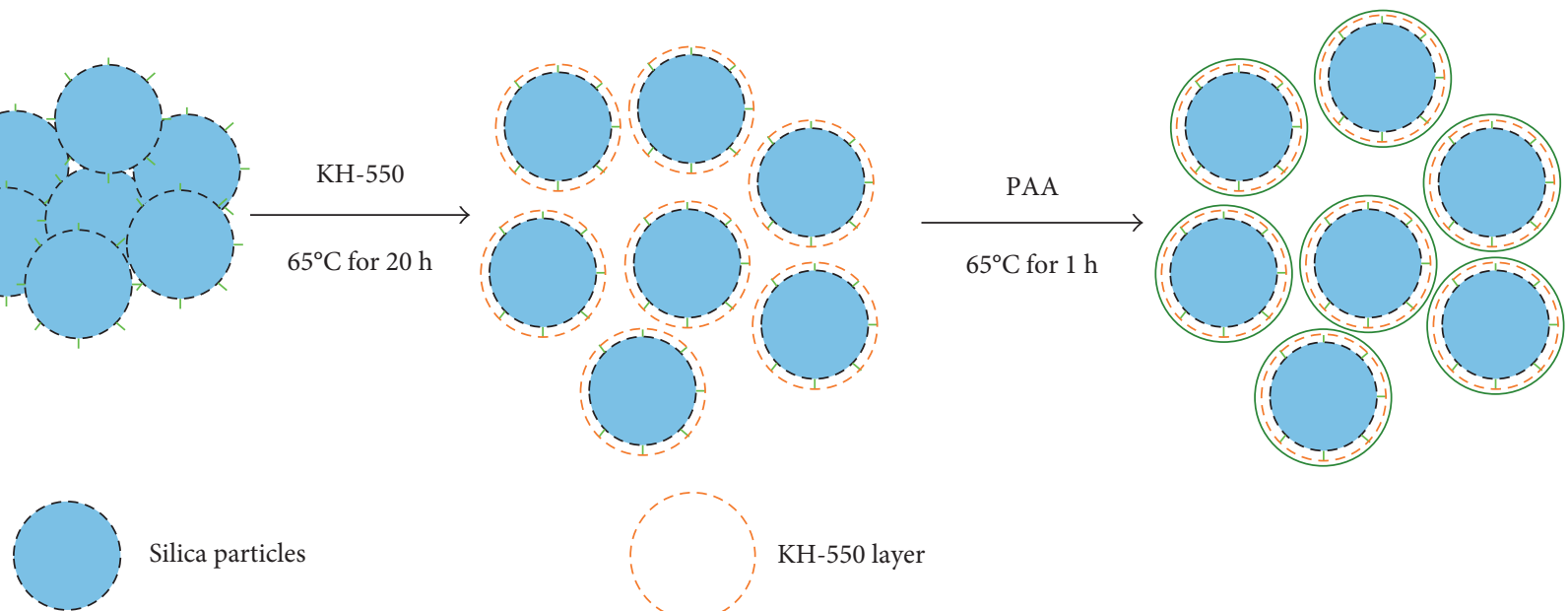

Silica particles

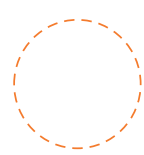

KH-550 layer

Hydroxy

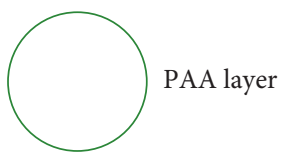

FIGURE 2: The brief schematic diagram of surface modification procedure.

Fourier transform infrared spectroscopy (FTIR, Nicolet 5700) was applied to analyse the surface groups of samples. $0.5 \mathrm{~g}$ of SF and MSF were, respectively, immersed in $500 \mathrm{~mL}$
$\mathrm{Ca}(\mathrm{OH})_{2}$-saturated solution for $0,6,12,24$, and 48 hours. Then the immersed samples were dried at $40^{\circ} \mathrm{C}$ in vacuum for $48 \mathrm{~h}$ and tested by FTIR. 
TABle 4: The dosage of modification agent used in different samples (g).

\begin{tabular}{lccc}
\hline Sample & $s$ & $k$ & $p$ \\
\hline MSF & 15 & 3 & 15 \\
MSF-2 & 15 & 6 & 15 \\
MSF-3 & 15 & 3 & 25 \\
\hline
\end{tabular}

TABLE 5: The mix proportion of cementitious paste.

\begin{tabular}{lcccc}
\hline Sample & W/B & \multicolumn{3}{c}{ Mix proportion (by mass) } \\
& & Cement & SF & MSF \\
\hline SF10 & 0.2 & 90 & 10 & 0 \\
MSF10 & 0.2 & 90 & 0 & 10 \\
\hline
\end{tabular}

The hydration heat of cementitious paste was analysed by isothermal conduction calorimetry with an 8-channel isothermal calorimeter (Thermometric TAM Air). About $20 \mathrm{~g}$ of sample with the W/B ratio of 0.5 was mixed and tested at $20^{\circ} \mathrm{C}$ for $72 \mathrm{~h}$. The mix proportions of paste samples are listed in Table 6 . The output results were normalized to the initial mass of cement.

\section{Results and Discussion}

3.1. Particle Dispersion Properties. The particle size distributions of initial SF and modified SF with different dosage of agent are shown in Figure 3. The particle size of SF ranged from $0.2 \mu \mathrm{m}$ to about $110 \mu \mathrm{m}$, and the results significantly changed for the modified SF. From the results, MSF particles exhibited the best dispersion. The maximum particle size of MSF was less than $100 \mu \mathrm{m}$, and the volume fraction of particles less than $5 \mu \mathrm{m}$ was higher than SF, which implied that more fine particles exist in MSF. However, if the dosage of KH-550 is increased, as the sample MSF-2, the particles with the size lager than $100 \mu \mathrm{m}$ was significantly increased, which means that the agglomeration becames more serious. As for the sample MSF-3, which was modified with more PAA, the minimum size was larger and the volume fraction of particles smaller than $5 \mu \mathrm{m}$ was lower than SF and MSF.

The particle size distribution results indicated that PAA surface modification efficiently changed the dispersion of SF. With the optimal ratio of raw SF to modification agents at 5 : $1: 5$, the agglomeration of modified MSF was improved, the maximum particle size was decreased, and the volume fraction of fine particles was larger than initial SF.

Based on the particle size distribution analysis results, MSF was optimally dispersed, and the following test was focused on MSF and compared with SF.

To directly evaluate the dispersion effect of surface modification, both SF and MSF particles were observed by SEM, and the images are presented in Figure 4. In Figure 4(a), it can be seen that although single SF particle was less than $1 \mu \mathrm{m}$, a large amount of particles agglomerated together to form a bulk cluster, and the size can reach several micrometres. After surface modification, the size of the agglomerated bulk cluster was much smaller, indicating that the dispersion was improved, as seen in Figure 4(b).
TABLE 6: The mix proportion of pastes in the isothermal conduction calorimetry test.

\begin{tabular}{lcccc}
\hline \multirow{2}{*}{ Number } & W/B & \multicolumn{3}{c}{ Mix proportion (by mass) (\%) } \\
& & Cement & SF & MSF \\
\hline P & 0.5 & 100 & - & - \\
PS & 0.5 & 90 & 10 & - \\
PS2 & 0.5 & 90 & - & 10 \\
\hline
\end{tabular}

3.2. Surface Properties. The surface properties and the stability of the surface agent in alkali condition were investigated by FTIR, and the curves for SF and MSF with different immersed time are shown in Figure 5. In Figure 5(a), the broadband at $3419 \mathrm{~cm}^{-1}$ can be assigned to the $\mathrm{O}-\mathrm{H}$ stretching vibration of $\mathrm{Si}-\mathrm{OH}$ and absorbed water, and the band at $1622 \mathrm{~cm}^{-1}$ is the bending of the hydroxyl group. The bands around $1120 \mathrm{~cm}^{-1}$ and $800 \mathrm{~cm}^{-1}$ are due to the asymmetric and symmetric stretching vibrations of $\mathrm{Si}-\mathrm{O}-\mathrm{Si}$, while the band around $474 \mathrm{~cm}^{-1}$ corresponds to the symmetric bending vibration of O-Si-O [47]. For MSF, shown in Figure 5(b), all typical absorbed bands from $\mathrm{SiO}_{2}$ were detected. In addition, the band at $1716 \mathrm{~cm}^{-1}$ was attributed to the stretching vibration of the carbonyl group from PAA, and band at $1552 \mathrm{~cm}^{-1}$ was assigned to the $\mathrm{N}-\mathrm{H}$ bending [48]. For the sample immersed in saturated calcium hydroxide solution for more than 6 hours, the absorbed band from carbonyl group cannot be detected anymore, but the band of $\mathrm{N}-\mathrm{H}$ bond at $1552 \mathrm{~cm}^{-1}$ still existed, and the intense of the peak was higher with the increased immersing time.

Based on the FTIR results, a possible reaction process of SF surface modification and the status of the surface layer in the alkali condition were proposed. Initial SF particles have many hydroxyl groups on its surface. When $\mathrm{KH}-550$ mixed with SF solution at $65^{\circ} \mathrm{C}$ for $20 \mathrm{~h}$, its silane end was hydrolysed and reacted with hydroxyl groups. After PAA was added, the polymer was hydrolysed again and immobilized by the amidogen group of $\mathrm{KH}-550$ and formed a PAA layer coated with the surface of SF particles. The schematic reaction process is presented in Figure 6. The molecular layer surrounded the SF particles would enlarge the distance between particles and prevent them to contact again. In addition, the carboxyl group outside often exhibits negative charge in solution, and the charge repulsion effect can push the closed particles away.

Once the MSF was in the alkali condition, the bond between PAA and KH-550 was broken after $6 \mathrm{~h}$, the outer layer falls off, and the amino groups were exposed on the surface. And the concentration of active amino groups was increased with time, which means that more PAA was fallen.

3.3. Hydration Calorimetry. The hydration heat results of cement pastes with two kinds of SF particles are presented in Figure 7. Figure 7(a) is the heat flow of cement hydration for the samples, and the curves were normalized to the mass of initial cement. After the initial decrease, the heat flow of the cement sample (P) started to increase at 2.1 hour and reached the maximum of $4.0 \mathrm{mw} / \mathrm{g}$ at 11.3 hour. While mixed with SF, the acceleration of heat flow started at 1.7 


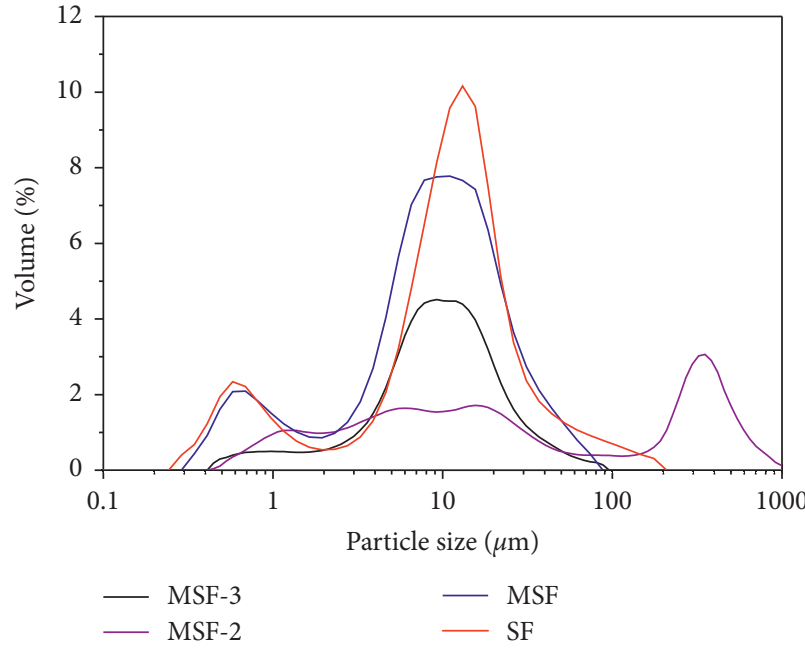

(a)

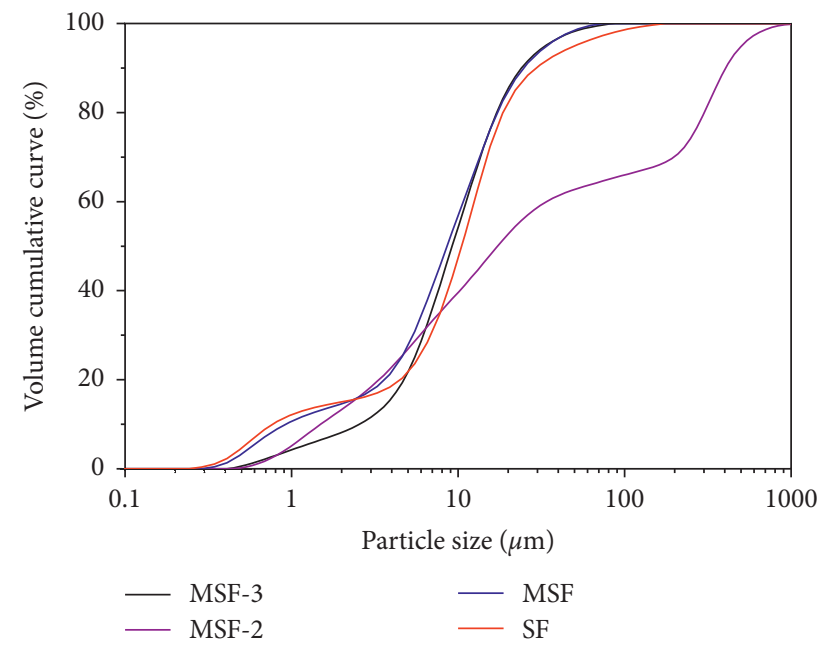

(b)

Figure 3: Particle size distribution (a) and cumulative curve (b) for samples with different dosages of the modified agents.

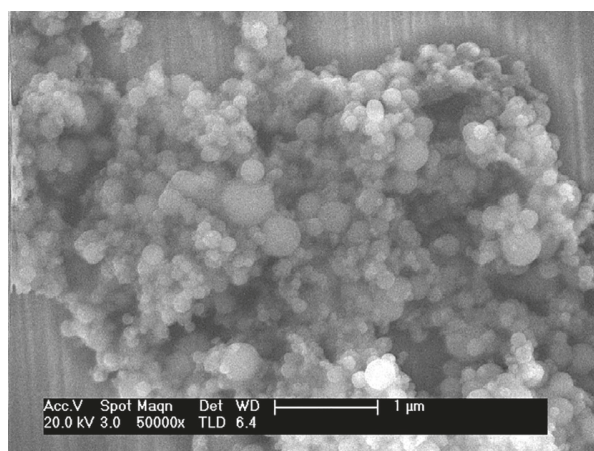

(a)

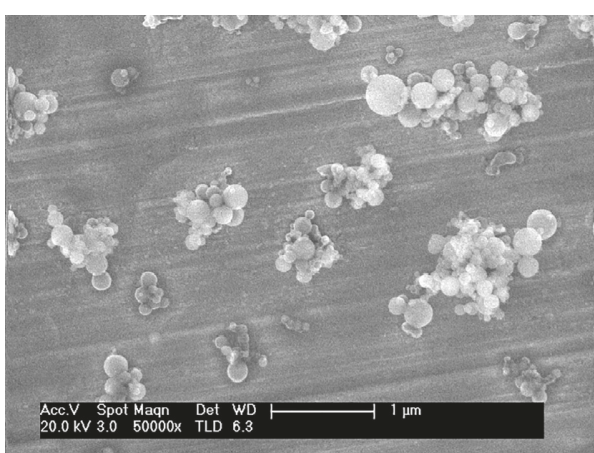

(b)

FIgURE 4: SEM images of SF (a) and MSF (b) particles.

hour, a little early than $\mathrm{P}$, and reached the peak of $5.6 \mathrm{mw} / \mathrm{g}$ at 10.4 hour and then sharply dropped. However, mixed with MSF, the cement hydration was deferred to 13.8 hour and then increased to the peak of $3.8 \mathrm{mw} / \mathrm{g}$ at 26.9 hour.

According to the literature $[47,49]$, the hydration process of cement can be divided into five stages: the initial reaction period, the induction period, the acceleration period, the deceleration period, and the stable reaction period. The results in Figure 7(a) demonstrated that compared with pure cement sample, SF particles shorten the acceleration period a little and significantly increased the hydration rate at the acceleration period. However, when mixed with MSF, the induction period of PS2 was about 12 hours longer than the sample $\mathrm{P}$, and the acceleration period was impacted insignificantly. However, the hydration rate of the sample PS2 was decreased slower than pure cement in the deceleration period.

The cumulative heat curves shown in Figure 7(b) corresponded with heat flow curves. The total amount and increasing rate of heat for the sample PS were the highest due to the high hydration rate in the acceleration period. On the contrary, samples with MSF released lowest heat due to the retardation at early time, but the increasing rate after $40 \mathrm{~h}$ was higher than cement because of the long acceleration period and relative high hydration speed in the deceleration period.

The fine SF particles have large specific surface area, which increased the surface available for reaction, resulting in acceleration in cement hydration. At the same time, a large amount of hydration products generated around the unreacted cement particles in short time, obstructing its further reaction, so that the reaction in the accelerating period was violent and terminated quickly. When SF was modified with the surface agent, although the fineness of particles increased, the hydrophilic PAA molecule blocked the available surface for cement hydration, leading to a restrained hydration rate at early age. In addition, the hydrophilic PAA layer absorbed mixing water, causing a retardation of cement hydration. However, with the increasing alkalinity generated from cement reaction, the PAA layer was supposed to peel off the particles, the shorter $\gamma$-aminopropyltriethoxysilane molecule cannot fully cover 

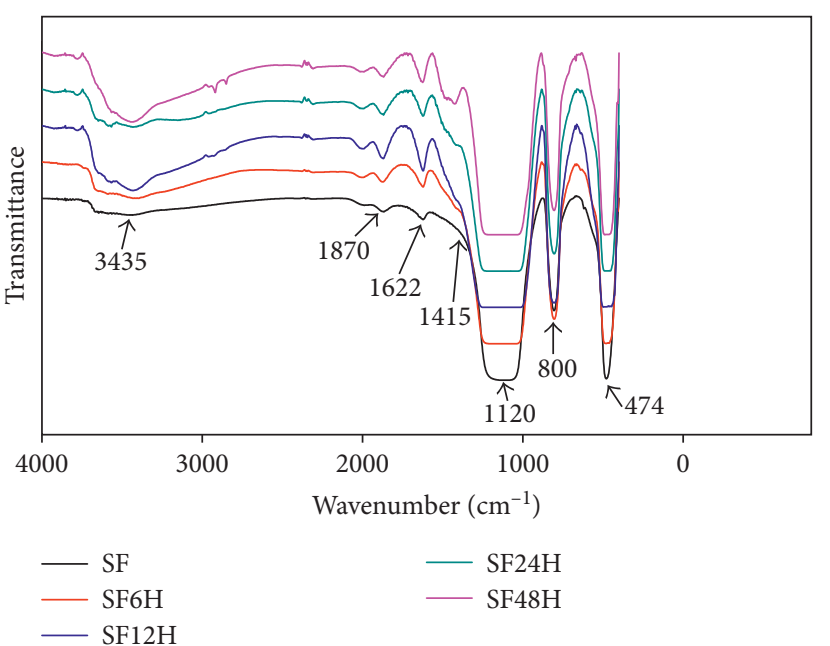

SF12H

(a)

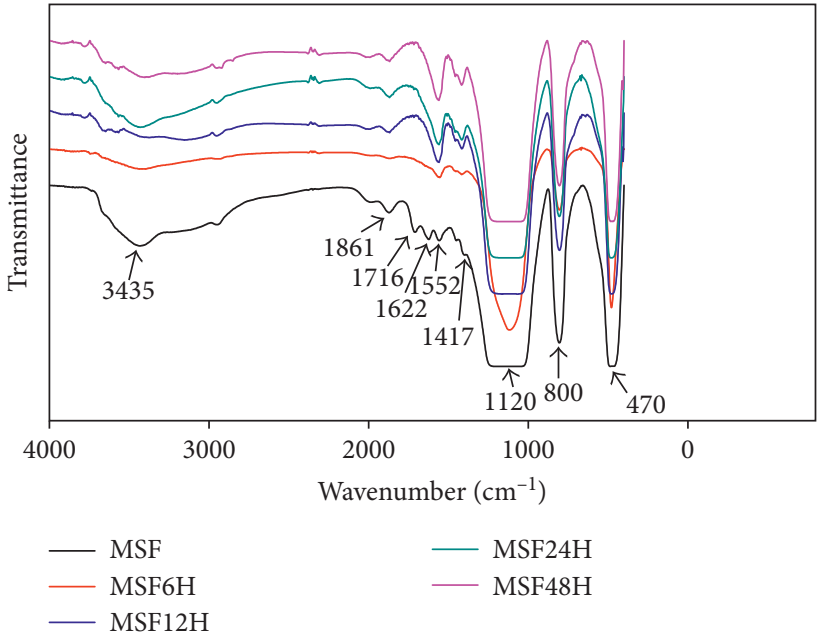

(b)

Figure 5: FTIR curves for SF (a) and MSF (b) with different immersed time.
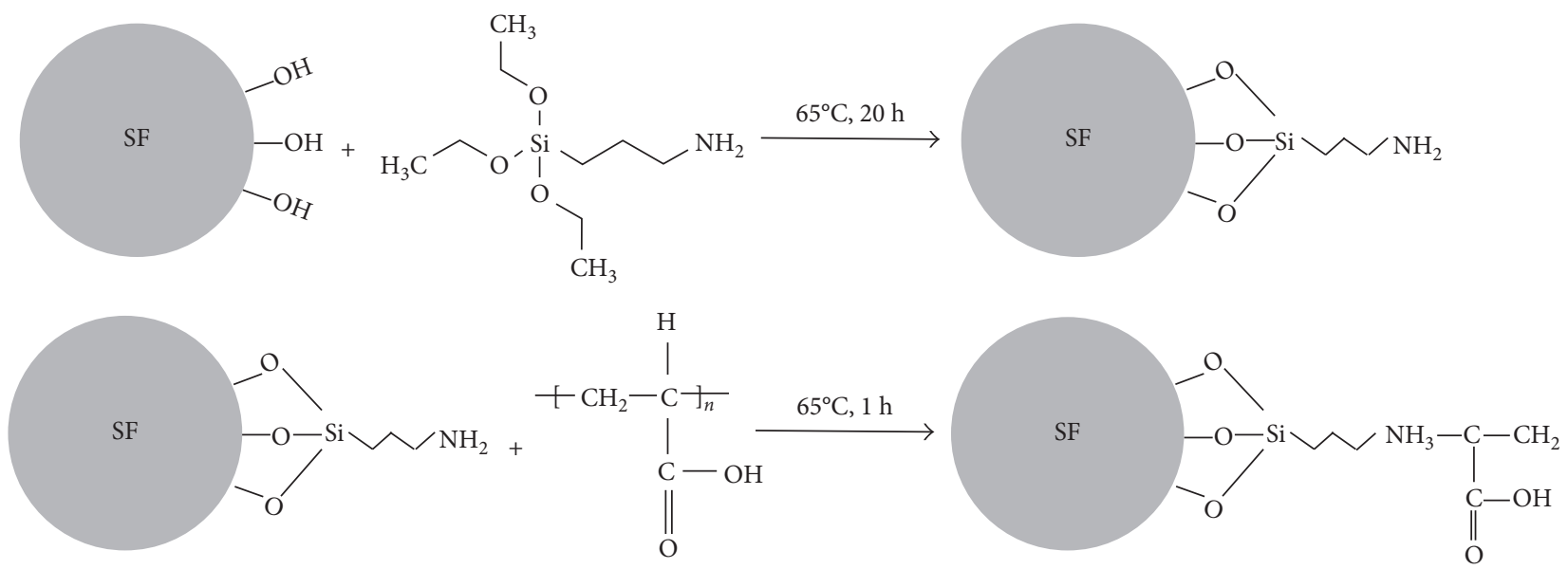

FIGURE 6: Schematic representation for surface modification reaction.

the particle surface, and part of the active surface exposed for cement hydration again so that the hydration rate in the deceleration period was relatively higher.

3.4. Morphology and Hydration Degree of Pastes. The morphology of cement hydration products was observed by BSE images, as shown in Figure 8. There were two primary phases in both samples. Due to the low $\mathrm{W} / \mathrm{B}$ and pozzolanic reaction of SF, calcium hydroxide was almost consumed. According to [46], the grey level of unreacted cement (UC) is brighter than C-S-H gel in BSE images. The C-S-H gel, which is dense and surrounds the UC particles, was supposed to be the inner C-S-H products, while the loose form of C-S-H was the outer product.

Compared with Figures 8(a) and 8(b), more C-S-H gel was generated in MSF10. To quantitate the evaluated the hydration degree of two paste samples, BSE images were analysed by software Image J, and the area fraction of UC in each sample was statistically calculated.
Based on the Image J software, the UC and C-S-H gel were distinguished by grey level; Figure 9 presents the BSE images for SF10 and MSF10 and the grey level range for different phases. Then, the area fraction of UC was analysed by software, and the average was carried out from thirty images for each sample. After calculation with (1), the average hydration degrees of SF10 and MSF10 were $54.4 \%$ and $63.2 \%$, respectively.

SF particles accelerated cement hydration at the acceleration period with their large active surface area, while the intense reaction of cement was finished quickly since much inner C-S-H gel was generated around the cement particle and stopped the continuous hydration. However, when mixed with MSF, the hydration process was gentle at early time because no active surface was available for cement hydration; the primary effect of MSF was physical filling effect. With the cement hydration proceeded, the outer PAA layer on MSF was dropped and the active surface was exposed to accelerate the hydration so that the hydration rates at the deceleration period and the stable reaction period were 


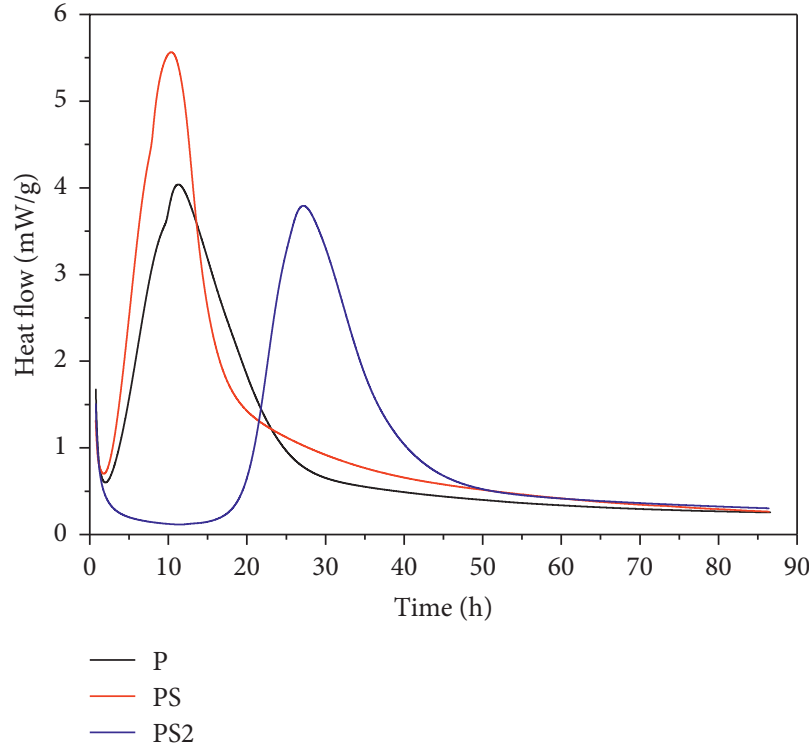

(a)

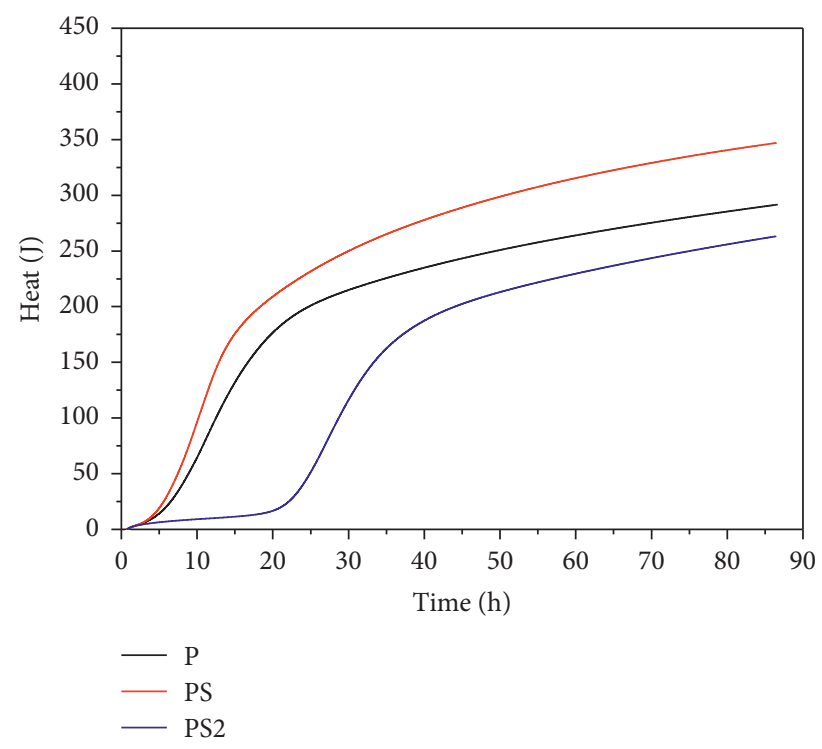

(b)

FIgURE 7: Isothermal calorimetry results of heat flow (a) and total hydration heat (b).

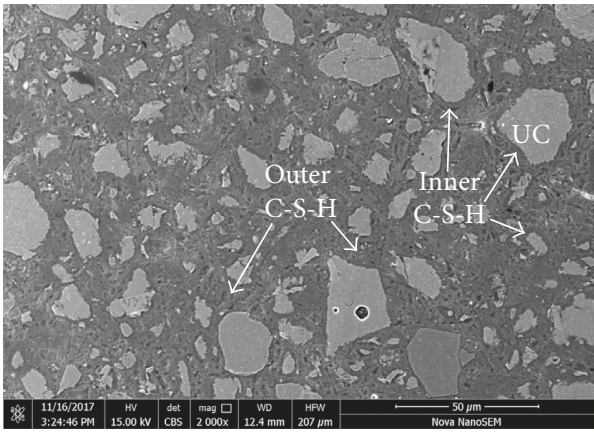

(a)

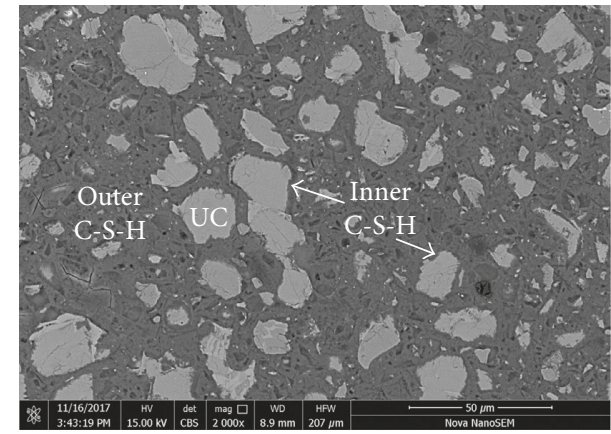

(b)

FIgure 8: The BSE images of cement hydrated with (a) SF and (b) MSF.

higher, leading to a relative higher hydration degree at long age.

\section{Conclusions}

Based on the results, the following conclusions can be drawn:

(1) A two-step surface modification was successfully applied to SF particles. The particle dispersion of the modified SF particles was improved significantly by the molecular position resistance and the space charge repulsion effect.

(2) The dosage of the dressing agent affected the dispersion efficiency. With the optimal ratio of SF to dressing agents of $5: 1: 5$ by weight, the particles exhibited the best dispersion. The maximum particle size was smaller, and the volume fraction of fine particles was larger than initial SF.

(3) The reaction process of surface modification was revealed using surface analysis. The carboxyl worked as the functional group of the PAA layer at the outside of MSF particles, and the layer cannot be stable in the alkali condition. The covered PAA layer peeled off in the alkali condition after 6 hours, exposing the amidogen group of KH-550.

(4) The SF particles with large reactive surface accelerated the hydration rate in the acceleration period, causing a rapid heat release and short acceleration and deceleration periods. The hydrophilic group of the PAA layer of MSF retarded the cement hydration for about 12 hours and restrained the hydration rate in the acceleration period. 

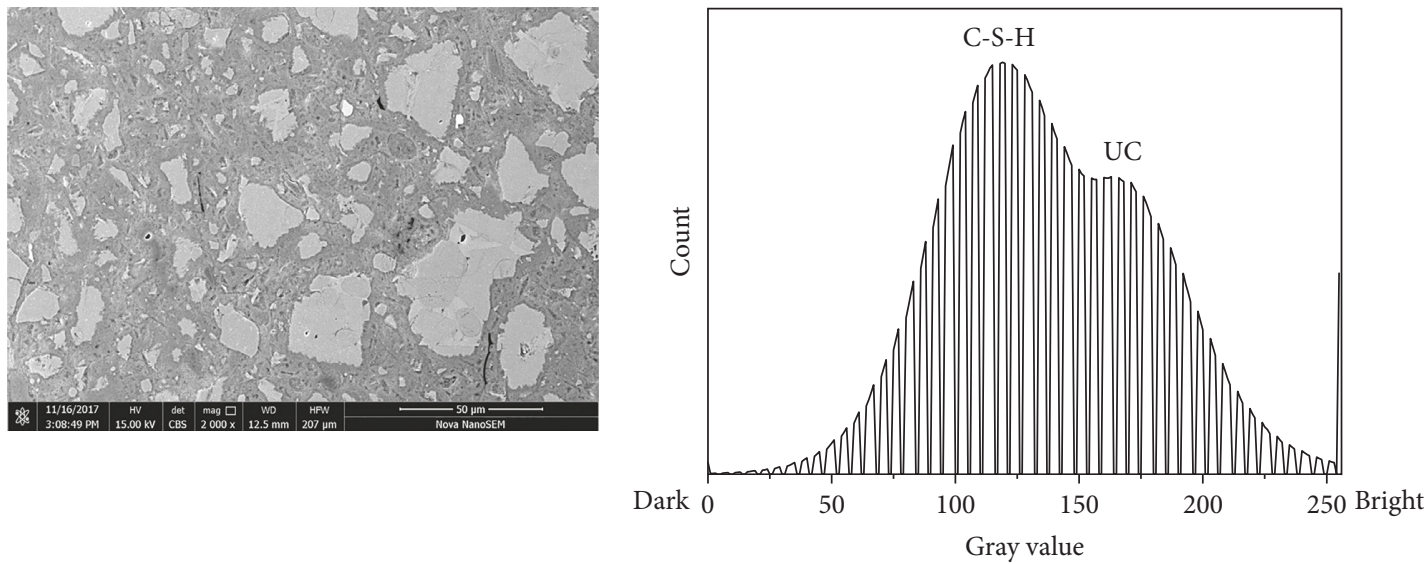

(a)

(b)

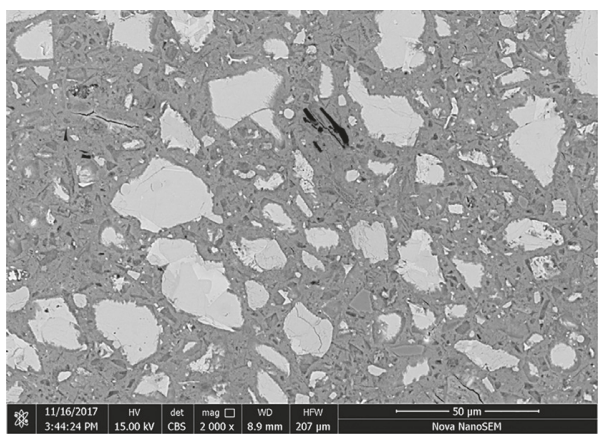

(c)

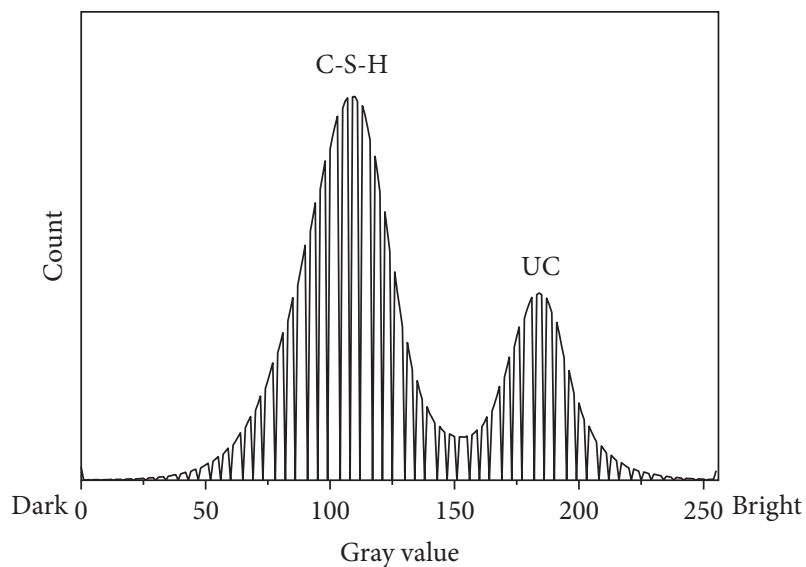

(d)

Figure 9: The BSE image (a) and grey level histogram (b) for SF10. The BSE image (c) and grey level histogram (d) for MSF10.

(5) The PAA layer of MSF was peeled off due to the raising alkalinity with hydration time. The hydration rate was decreased slowly in the deceleration period.

(6) The amount of inner C-S-H products of cement with SF was large due to the intensive hydration process. The hydration degree of cement with MSF was higher than that with SF. The moderated hydration of cement brought a continuous hydration reaction for longer time.

\section{Data Availability}

(1) The particle size distribution data, (2) the SEM image data, (3) the FTIR data, (4) the isothermal calorimetry data, (5) the BSE image data, and (6) the grey level histogram data used to support the findings of this study are included within the article.

\section{Conflicts of Interest}

The authors declare that there are no conflicts of interest regarding the publication of this paper.

\section{Acknowledgments}

This work was supported by the National Natural Science Foundation of China (Grant nos. 51438003 and 51678142) and partly supported by the National Basic Research Program of China (Grant no. 2015CB655102), and a Plan of Six Peak Talents in Jiangsu Province (Grant no. JZ-004), and the Fundamental Research Funds for the Central Universities.

\section{References}

[1] M. S. M. Norhasri, M. S. Hamidah, and A. M. Fadzil, "Applications of using nano material in concrete: a review," Construction and Building Materials, vol. 133, pp. 91-97, 2017.

[2] H. Yang and Y. Che, "Effects of nano- $\mathrm{CaCO}_{3} /$ limestone composite particles on the hydration products and pore structure of cementitious materials," Advances in Materials Science and Engineering, vol. 2018, Article ID 5732352, 8 pages, 2018.

[3] A. H. Shekari and M. S. Razzaghi, "Influence of nano particles on durability and mechanical properties of high performance concrete," Procedia Engineering, vol. 14, pp. 3036-3041, 2011. 
[4] S. Kawashima, P. Hou, D. J. Corr, and S. P. Shah, "Modification of cement-based materials with nanoparticles," Cement and Concrete Composites, vol. 36, pp. 8-15, 2013.

[5] M. Safiuddin, M. Gonzalez, J. Cao, and S. L. Tighe, "State-ofthe-art report on use of nano-materials in concrete," International Journal of Pavement Engineering, vol. 15, no. 10, pp. 940-949, 2014.

[6] C. Jiang, H. Yuan, C. Lu, Z. Xu, and D. Lu, "The effect of nanoparticles on the properties of calcium aluminate cement pastes at high temperatures," Advances in Cement Research, vol. 30, pp. 195-203, 2018.

[7] R. Ma, L. Guo, W. Sun, J. Liu, and J. Zong, "Strength-enhanced ecological ultra-high performance fibre-reinforced cementitious composites with nano-silica," Materials and Structures, vol. 50, p. 166, 2017.

[8] P. Zhang, N. Xie, X. Cheng, L. Feng, P. Hou, and Y. Wu, "Low dosage nano-silica modification on lightweight aggregate concrete," Nanomaterials and Nanotechnology, vol. 8, 2018.

[9] W. N. Meng and K. H. Khayat, "Effect of graphite nanoplatelets and carbon nanofibers on rheology, hydration, shrinkage, mechanical properties, and microstructure of UHPC," Cement and Concrete Research, vol. 105, pp. 64-71, 2018.

[10] J. Xu, B. B. Wang, and J. Q. Zuo, "Modification effects of nanosilica on the interfacial transition zone in concrete: a multiscale approach," Cement and Concrete Composites, vol. 81, pp. 1-10, 2017.

[11] M. Rupasinghe, R. S. Nicolas, P. Mendis, M. Sofi, and T. Ngo, "Investigation of strength and hydration characteristics in nano-silica incorporated cement paste," Cement and Concrete Composites, vol. 80, pp. 17-30, 2017.

[12] B. Han, Z. Wang, S. Zeng et al., "Properties and modification mechanisms of nano-zirconia filled reactive powder concrete," Construction and Building Materials, vol. 141, pp. 426-434, 2017.

[13] W. J. Long, B. X. Xiao, Y. C. Gu, and F. Xing, "Micro- and macro-scale characterization of nano- $\mathrm{SiO}_{2}$ reinforced alkali activated slag composites," Materials Characterization, vol. 136, pp. 111-121, 2018.

[14] B. Han, S. Sun, S. Ding, L. Zhang, X. Yu, and J. Ou, "Review of nanocarbon-engineered multifunctional cementitious composites," Composites Part A: Applied Science and Manufacturing, vol. 70, pp. 69-81, 2015.

[15] J. Camiletti, A. M. Soliman, and M. L. Nehdi, "Effect of nanocalcium carbonate on early-age properties of ultra-highperformance concrete," Magazine of Concrete Research, vol. 65, no. 5, pp. 297-307, 2013.

[16] J. Chen, S.-C. Kou, and C.-S. Poon, "Hydration and properties of nano-TiO2 blended cement composites," Cement and Concrete Composites, vol. 34, no. 5, pp. 642-649, 2012.

[17] J. Camiletti, A. M. Soliman, and M. L. Nehdi, "Effects of nanoand micro-limestone addition on early-age properties of ultra-high-performance concrete," Materials and Structures, vol. 46, no. 6, pp. 881-898, 2012.

[18] T. H. Liou, "Preparation and characterization of nanostructured silica from rice husk," Materials Science and Engineering: $A$, vol. 364, no. 1-2, pp. 313-323, 2004.

[19] D. Bonen and K. H. Khayat, "Characterization and pozzolanic properties of silica fume stored in an open pond," Cement and Concrete Composites, vol. 25, no. 2, pp. 395-407, 1995.

[20] V. G. Papadakis, "Experimental investigation and theoretical modeling of silica fume activity in concrete," Cement and Concrete Research, vol. 29, no. 1, pp. 79-86, 1999.
[21] G. Quercia, J. J. G. van der Putten, G. Huesken, and H. J. H. Brouwers, "Photovoltaic's silica-rich waste sludge as supplementary cementitious material (SCM)," Cement and Concrete Research, vol. 54, pp. 161-179, 2013.

[22] W. Xu, T. Lo, W. Wang, D. Ouyang, P. Wang, and F. Xing, "Pozzolanic reactivity of silica fume and ground rice husk ash as reactive silica in a cementitious system: a comparative study," Materials, vol. 9, no. 3, p. 146, 2016.

[23] S. Diamond and S. Sahu, "Densified silica fume: particle sizes and dispersion in concrete," Materials and Structures, vol. 39, no. 9, pp. 849-859, 2006.

[24] T. Oertel, F. Hutter, R. Tanzer, U. Helbig, and G. Sextl, "Primary particle size and agglomerate size effects of amorphous silica in ultra-high performance concrete," Cement and Concrete Composites, vol. 37, pp. 61-67, 2013.

[25] J. Bernal, E. Reyes, J. Massana, N. León, and E. Sánchez, “Fresh and mechanical behavior of a self-compacting concrete with additions of nano-silica, silica fume and ternary mixtures," Construction and Building Materials, vol. 160, pp. 196-210, 2018.

[26] M. Valipour, M. Shekarchi, and M. Arezoumandi, "Chlorine diffusion resistivity of sustainable green concrete in harsh marine environments," Journal of Cleaner Production, vol. 142, pp. 4092-4100, 2017.

[27] P. Duan, C. Yan, and W. Zhou, "Compressive strength and microstructure of fly ash based geopolymer blended with silica fume under thermal cycle," Cement and Concrete Composites, vol. 78, pp. 108-119, 2017.

[28] T. Oertel, F. Hutter, U. Helbig, and G. Sextl, "Amorphous silica in ultra-high performance concrete: first hour of hydration," Cement and Concrete Research, vol. 58, pp. 131-142, 2014.

[29] S. Mallakpour and F. Marefatpour, "An effective and environmentally friendly method for surface modification of amorphous silica nanoparticles by biodegradable diacids derived from different amino acids," Synthesis and Reactivity in Inorganic Metal-Organic and Nano-Metal Chemistry, vol. 45, no. 3, pp. 376-380, 2015.

[30] R. S. Edwin, M. De Schepper, E. Gruyaert, and N. De Belie, "Effect of secondary copper slag as cementitious material in ultra-high performance mortar," Construction and Building Materials, vol. 119, pp. 31-44, 2016.

[31] Z. Zhang, B. Zhang, and P. Yan, "Hydration and microstructures of concrete containing raw or densified silica fume at different curing temperatures," Construction and Building Materials, vol. 121, pp. 483-490, 2016.

[32] B. Maiti, K. Bauri, M. Nandi, and P. De, "Surface functionalized nano-objects from oleic acid-derived stabilizer via nonpolar raft dispersion polymerization," Journal of Polymer Science Part A: Polymer Chemistry, vol. 55, no. 2, pp. 263-273, 2017.

[33] Z. Peng, Q. Li, H. Li, and Y. Hu, "Polyethylene-modified nano silica and its fine dispersion in polyethylene," Industrial and Engineering Chemistry Research, vol. 56, no. 20, pp. 58925898, 2017.

[34] B. G. Ma, Q. Jiang, J. Huang et al., "One-pot in-situ surface modification of silica nanosphere by siloxane-coupled polycarboxylate with improved aqueous dispersion stability," Journal of Sol-Gel Science and Technology, vol. 83, no. 3, pp. 582-589, 2017.

[35] L. Chen, Z. Jia, Y. Tang, L. Wu, Y. Luo, and D. Jia, "Novel functional silica nanoparticles for rubber vulcanization and reinforcement," Composites Science and Technology, vol. 144, pp. 11-17, 2017. 
[36] F. Dalas, S. Pourchet, A. Nonat, D. Rinaldi, S. Sabio, and M. Mosquet, "Fluidizing efficiency of comb-like superplasticizers: the effect of the anionic function, the side chain length and the grafting degree," Cement and Concrete Research, vol. 71, pp. 115-123, 2015.

[37] W. Meng, P. Lunkad, A. Kumar, and K. Khayat, "Influence of silica fume and polycarboxylate ether dispersant on hydration mechanisms of cement," Journal of Physical Chemistry C, vol. 120, no. 47, pp. 26814-26823, 2016.

[38] D.-Y. Lei, L.-P. Guo, W. Sun, J. Liu, X. Shu, and X.-L. Guo, “A new dispersing method on silica fume and its influence on the performance of cement-based materials," Construction and Building Materials, vol. 115, pp. 716-726, 2016.

[39] Y. Gu, Q. Ran, W. She, and J. Liu, "Modifying cement hydration with NS@PCE core-shell nanoparticles," Advances in Materials Science and Engineering, vol. 2017, Article ID 3823621, 13 pages, 2017.

[40] M. R. Shaik, M. Kuniyil, M. Khan et al., "Modified polyacrylic acid-zinc composites: synthesis, characterization and biological activity," Molecules, vol. 21, no. 3, p. 292, 2016.

[41] I. V. Kavetskaya, V. M. Kashkarov, D. A. Minakov, P. V. Seredin, and A. S Lenshin, "A study of the role of polyacrylic acid in the surface modification of porous silicon with the aim of enhancing and stabilizing silicon photoluminescence," Journal of Surface Investigation, vol. 9, no. 4, pp. 844-847, 2015.

[42] X. Shu, Q. Ra, J. Liu et al., "Tailoring the solution conformation of polycarboxylate superplasticizer toward the improvement of dispersing performance in cement paste," Construction and Building Materials, vol. 116, pp. 289-298, 2016.

[43] C. W. Miao, Q. P. Ran, J. P. Liu, Y. L. Mao, Y. Shang, and J. F. Sha, "New generation amphoteric comb-like copolymer superplasticizer and its properties," Polymers and Polymer Composites, vol. 19, pp. 1-8, 2011.

[44] G. Tan, K. Ouyang, H. Wang et al., "Effect of amino-, methyland epoxy-silane coupling as a molecular bridge for formatting a biomimetic hydroxyapatite coating on titanium by electrochemical deposition," Journal of Materials Science and Technology, vol. 32, no. 9, pp. 956-965, 2016.

[45] P. Xu, X. Yan, P. Cong, X. Zhu, and D. Li, "Silane coupling agent grafted graphene oxide and its modification on polybenzoxazine resin," Composite Interfaces, vol. 24, no. 7, pp. 635-648, 2017.

[46] F. Han, J. Liu, and P. Yan, "Comparative study of reaction degree of mineral admixture by selective dissolution and image analysis," Construction and Building Materials, vol. 114, pp. 946-955, 2016.

[47] Y. Iqbal, H. Bae, I. Rhee, and S. Hong, "Magnetic heating of silica-coated manganese ferrite nanoparticles," Journal of Magnetism and Magnetic Materials, vol. 409, pp. 80-86, 2016.

[48] M. Lu, X. Gao, P. Liu et al., "Photo- and thermo-oxidative aging of polypropylene filled with surface modified fumed nanosilica," Composites Communications, vol. 3, pp. 51-58, 2017.

[49] I. Pane and W. Hansen, "Investigation of blended cement hydration by isothermal calorimetry and thermal analysis," Cement and Concrete Research, vol. 35, no. 6, pp. 1155-1164, 2005. 


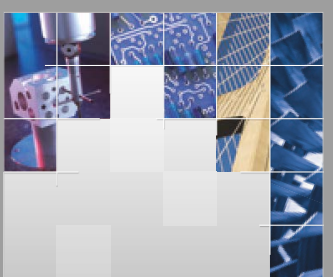

\section{Enfincering}
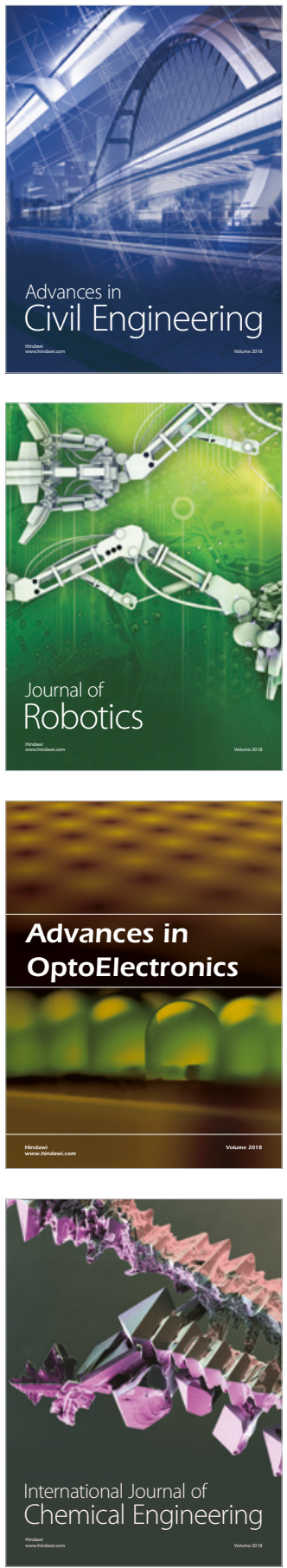

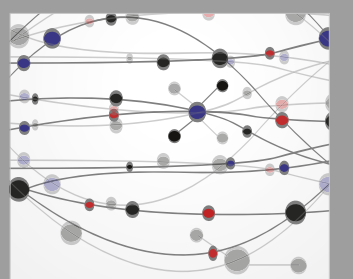

\section{Rotating \\ Machinery}

The Scientific World Journal

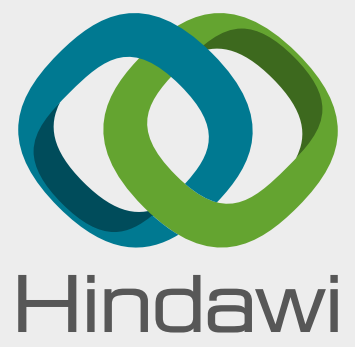

Submit your manuscripts at

www.hindawi.com
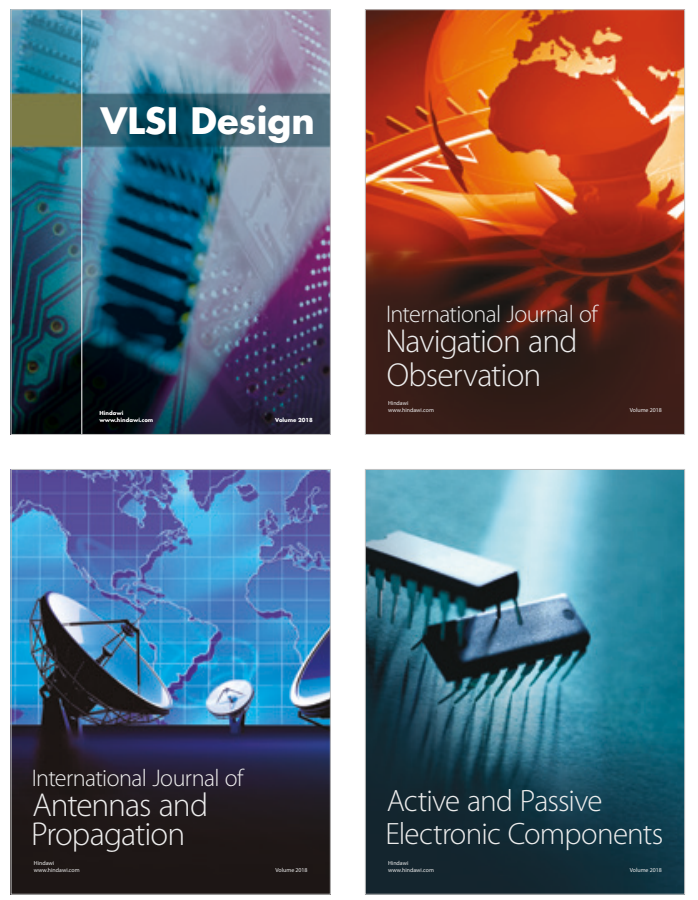
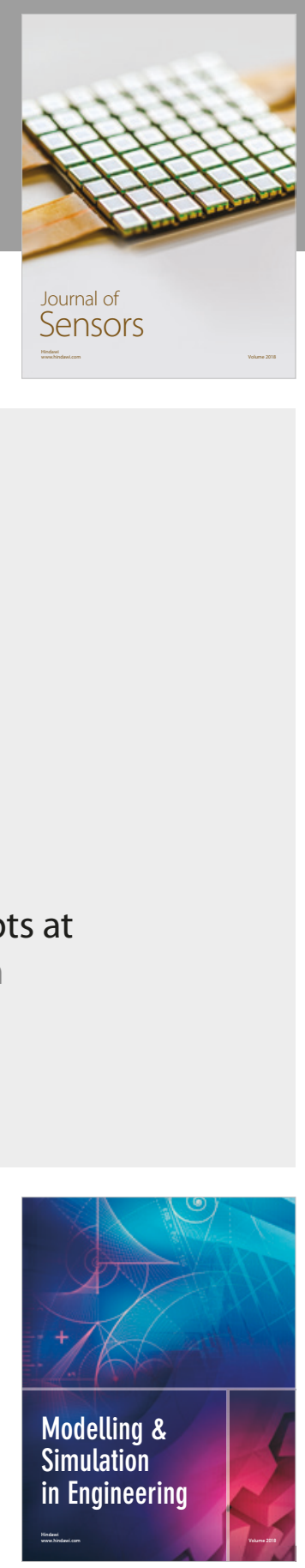

\section{Advances \\ Multimedia}
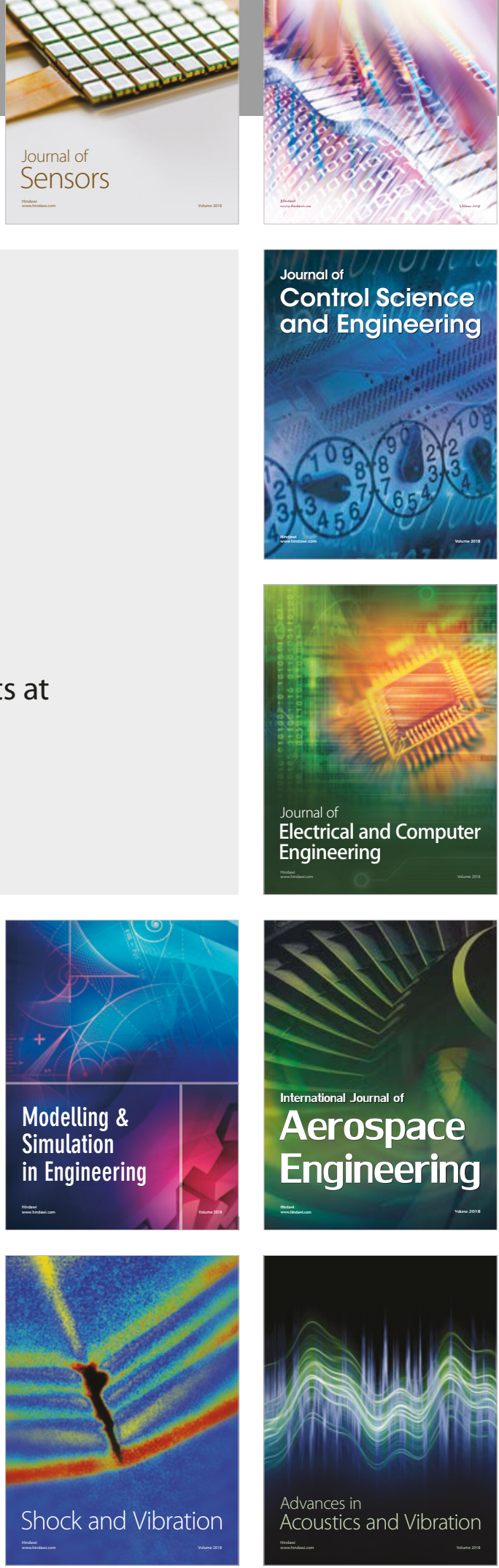